\title{
Desempenho Comparativo de Seis Grupos de Cruzamento Holandês/Guzerá. 11. Peso e Altura de Vacas e Novilhas ${ }^{1}$
}

\author{
Ana Paula Madureira ${ }^{2}$, Fernando Enrique Madalena ${ }^{3}$, Roberto Luiz Teodoro ${ }^{4}$
}

\begin{abstract}
RESUMO - Foram estudadas as características peso corporal, altura à cernelha e razão peso/altura (um indicador da condição corporal) de, respectivamente, 263, 232 e 232 vacas e 171, 135 e 135 novilhas, de seis diferentes composições genéticas Holandês Vermelho e Branco (HVB) x Guzerá (Guz): 1/4, 1/2, 5/8, 3/4, 7/8 e $\geq 31 / 32$ HVB. Para as vacas o modelo [1] incluiu os efeitos fixos de estado reprodutivo, estádio da lactação, estação de pesagem, classe de fazenda, idade e grupo genético, interações duplas e o efeito aleatório de vaca e para as novilhas, os efeitos fixos de estação de pesagem, classe de fazenda, idade e grupo genético, a interação de estação x idade e o efeito aleatório de novilha. O modelo [2] foi igual ao modelo [1], exceto para o efeito de grupo genético, que foi substituído por regressões sobre a fração de HVB e a heterozigose racial, para estimar a diferença aditiva entre as raças $(g \mathrm{I}, \mathrm{HVB}-\mathrm{Guz})$ e a heterose $\left(h^{\mathrm{I}}\right)$. A altura de vacas e novilhas não apresentou heterose, mas diminuiu linearmente com a fração de HVB (vacas, $g^{\mathrm{I}}=-9,75+2,42 \mathrm{~cm}$, novilhas, $-10,38+2,72 \mathrm{~cm}$ ). A estimativa de $g^{\mathrm{I}}$ não foi significativamente diferente de zero para peso corporal de vacas ou novilhas, mas a heterose foi muito importante $\left(\right.$ vacas, $h^{\mathrm{I}}=51,42+13,40$ $\mathrm{kg}$, novilhas, $h^{\mathrm{I}}=109,77+32,97 \mathrm{~kg}$ ). Para peso/altura as estimativas em vacas e novilhas foram, respectivamente, $g^{\mathrm{I}}=0,27+0,10 \mathrm{e} 0,41+0,24$ $\mathrm{kg} / \mathrm{cm}$ e $h^{\mathrm{I}}=0,36+0,08$ e $0,65+0,24 \mathrm{~kg} / \mathrm{cm}$. Testes de $\mathrm{F}$ da variação no modelo [1] ajustado após o modelo [2] não foram significativos, indicando que a epistasia ou outro efeito genético não incluído no modelo [2] não foram importantes nestas características, em nenhuma das duas categorias. O grupo genético mais pesado e com maior relação peso/altura foi o $1 / 2 \mathrm{HVB}\left(\mathrm{F}_{1}\right)$.
\end{abstract}

Palavras-chave: peso corporal, altura na cernelha, vacas mestiças, heterose, cruzamentos

\section{Comparative Performance of Six Holstein-Friesian/Guzera Crossbred Groups. 11. Weight and Height of Cows and Heifers}

\begin{abstract}
Weight, height at withers and the weight/height ratio (an indicator of body condition) of respectively, 263, 232 and 232 cows and 171, 135 and 135 heifers were studied. Animals were of six red and white Holstein-Friesian (HF) x Guzerá (Guz) crosses: $1 / 4,1 / 2,5 / 8,3 / 4,7 / 8$ and $\geq 31 / 32 \mathrm{HF}$. Model [1] for cows included the fixed effects of reproductive status, days in milk, season when weighted, farm class, age and genetic group, two-factor interactions and the random effect of cow, and for heifers the fixed effects of season, farm class, age and genetic group, the season $\mathrm{x}$ age interaction and the random effect of heifer. Model [2] was the same as model [1] except that the regressions on HF fraction and breed heterozygocity substituted for the genetic group classification effect, to estimate the breed additive difference ( $\left.g^{\mathrm{I}}, \mathrm{HF}-\mathrm{Guz}\right)$ and heterosis $\left(h^{\mathrm{I}}\right)$. Height of cows or heifers did not show heterosis but declined linearly with the HF fraction (cows, $g^{\mathrm{I}}=-9.75+2.42 \mathrm{~cm}$, heifers, $-10.38+2.72 \mathrm{~cm}$ ). In both categories, the liveweight $g^{\mathrm{I}}$ estimates did not significantly differ from zero, while heterosis was very important $\left(h^{\mathrm{I}}=51.42+13.40 \mathrm{~kg}\right.$ in cows and $h^{\mathrm{I}}=109.77+32.97 \mathrm{~kg}$ in heifers $)$. For weight/height the respective estimates in cows and heifers were $g^{\mathrm{I}}=0.27+0.10$ and $0.41+0.24 \mathrm{~kg} / \mathrm{cm}$ and $h^{\mathrm{I}}=0.36+0.08$ and $0.65+0.24 \mathrm{~kg} / \mathrm{cm}$. F-tests on the extra variation due to fitting model [1] after model [2] were not significant, indicating that epistasis or other genetic effects not included in model [2] were of little importance. The heaviest cross was the $\mathrm{F}_{1}$, which also showed the highest weight/height ratio.
\end{abstract}

Key Words: liveweight, withers height, crossbred cows, heterosis, crossbreeding

\section{Introdução}

O peso corporal é importante componente da eficiência da produção de gado de leite, já que mais de $50 \%$ das exigências de energia total podem ser atribuídos à mantença (Cue et al., 1996). A importância econômica do peso corporal das vacas leiteiras foi salientada por vários autores (Dickerson, 1973; Marshall et al., 1984) e confirmada com resultados brasileiros por Vercesi Filho et al. (2000).

Como o peso é bastante influenciado por fatores ambientais e sofre flutuações periódicas, as mensurações lineares de medidas esqueléticas, como a altura na cernelha, forneceriam informações mais

\footnotetext{
${ }_{1}^{1}$ Parte da Dissertação de Mestrado em Zootecnia da primeira autora apresentada à UFMG. Apoiado pelo CNPq e pela CAPES.

2Departamento de Zootecnia, Escola de Veterinária da UFMG. E.mail: anapaula_mad@yahoo.com

${ }^{3}$ Departamento de Zootecnia, Escola de Veterinária da UFMG. E.mail: fermadal@dedalus.lcc.ufmg.br, Endereço para correspondência: Cx.P. 567, 30123-970 Belo Horizonte, MG.

${ }^{4}$ EMBRAPA - Gado de Leite E.mail: rteodoro@cnpgl.embrapa.br
} 
precisas e confiáveis do tamanho dos animais (Cartwright, 1979). Segundo Mckay et al. (1989), Winkler et al. (1992) e Winkler (1993), as medidas corporais lineares apresentam maior repetibilidade que o peso corporal, não sendo influenciadas por variações no conteúdo gastrointestinal e nos níveis de hidratação (Nicholson \& Sayers, 1987).

A razão peso/altura é um bom indicador da condição corporal (Klosterman et al., 1968; Nelsen et al., 1985), que influi nos requerimentos nutricionais e no desempenho reprodutivo das vacas (Thompson et al., 1983). Mason et al. (1957) sugeriram a razão produção de leite/altura na cernelha como o melhor critério de seleção para eficiência alimentar.

Resultados de Perotto et al. (1997), no Brasil, e de vários autores em outros países tropicais indicaram que, nos cruzamentos de Holandês x zebu, o peso corporal das fêmeas tem sido maior no cruzamento F1 e diminuído com a heterozigose em outros cruzamentos (Katpatal, 1977; Bhat et al., 1978; Sharma et al., 1981; Narayanaswamy et al., 1984; Pandey et al., 1985; Roy e Tripathi, 1991). Modelos de predição do desempenho de cruzamentos são necessários para se desenvolverem sistemas que utilizem economicamente os recursos genéticos (Dickerson, 1969). O modelo aditivo-dominante foi adequado para descrever o peso à puberdade de fêmeas em cruzamentos de Holandês/Guzerá no Brasil (Teodoro et al., 1984).

Este estudo, que faz parte do projeto "Estratégias de cruzamentos entre raças leiteiras na Região $\mathrm{Su}-$ deste" (Madalena, 1993), foi conduzido com o objetivo de avaliar o peso corporal, a altura na cernelha e a razão entre peso/altura para vacas e novilhas de seis grupos genéticos Holandês/Guzerá, visando obter estimativas da diferença entre as raças e da heterose para estas características, assim como testar a validade do modelo aditivo-dominante.

\section{Material e Métodos}

Foram estudadas as características de peso corporal, altura à cernelha e razão peso/altura $(\mathrm{P} / \mathrm{A})$ de, respectivamente, 263, 232 e 232 vacas e 171,135 e 135 novilhas, de seis diferentes composições genéticas Holandês Vermelho e Branco (HVB) x Guzerá (Guz), com frações $1 / 4,1 / 2,5 / 8,3 / 4,7 / 8$ e $\geq 31 / 32$ de HVB. Os grupos serão referenciados por estas frações. Os grupos $1 / 2,3 / 4,7 / 8$ e $\geq 31 / 32$ eram $F 1$ e retrocruzamentos para HVB, filhas de touros desta raça. Com algumas exceções, os mesmos touros foram utilizados para gerar esses quatro grupos genéticos. As $1 / 4$ eram filhas de touros Guz e as 5/8 eram "bimestiças", filhas de touros e vacas $5 / 8 \mathrm{HVB} / \mathrm{Guz}$. Na amostra deste estudo foram utilizados 12 pais $\mathrm{HVB}, 14 \mathrm{Guz}$ e oito 5/8.

Os animais foram produzidos na Fazenda Experimental Santa Mônica, Valença, RJ, de propriedade da EMBRAPA-Gado de Leite, e distribuídos, com média de idade de 22 meses e de peso de $263 \mathrm{~kg}$, a fazendas cooperadoras na Região Sudeste do Brasil, onde foram manejadas de acordo com as práticas usuais de cada fazenda. Com poucas exceções, cada fazenda recebeu seis novilhas, uma de cada grupo genético, fazendo-se sempre um esforço para minimizar a diferença de idade entre os animais, que, em média, foi de 36 dias, com média de amplitude de 83 dias (Madalena, 1993).

Em parte das fazendas, de mais fácil acesso, foram coletados dados de peso corporal e altura na cernelha dos animais. As pesagens foram realizadas com balança-carreta portátil de 200 gramas de precisão. As vacas secas a serem pesadas foram submetidas a jejum de água e comida por 16 horas (Madalena, 1964). A altura na cernelha foi medida por meio de trena métrica. Existiam duas balanças portáteis, uma na EMBRAPA - Gado de Leite, Coronel Pacheco, MG, e outra no hoje Centro de Pesquisa de Pecuária do Sudeste - EMBRAPA, São Carlos, SP. Inicialmente, previam-se duas pesagens de todos os animais nestas fazendas, sendo uma na estação seca e outra na estação chuvosa, o que foi basicamente mantido, com algumas exceções, até o encerramento do acompanhamento, o que ocorreu por falta de recursos em 1987.

Os animais nasceram no período de 1977 a 1981 e foram pesados no período de 1981 a 1987. A idade das vacas na ocasião das pesagens variou de três a nove anos e o número de pesagens por vaca, de 1 a 11 (média 5,6). A idade das novilhas variou de dois a cinco anos e o número de pesagens por animal, de um a sete (média 1,7). O número de observações de altura foi menor, em virtude de alguns animais não terem sido medidos.

Foi estimado o estado reprodutivo a partir da previsão de uma gestação com duração de 282 dias (Lemos et al., 1984), a qual foi subtraída da data do parto para se obter a data estimada da concepção. Os dados foram agrupados em cinco classes de estado reprodutivo no dia da pesagem: 1) animais não gestantes, 2) animais de 1 a 94 dias de gestação, 3) de 95 a 188 dias, 4) animais de 189 a 282 dias e 5) animais com estado reprodutivo desconhecido (eliminados 
antes do último parto). Para as vacas foram consideradas quatro classes de estádio da lactação: 1) de 1 a 100 dias, 2) de 101 a 200 dias, 3) acima de 200 dias e 4) vaca seca. Foram consideradas duas épocas de pesagem ou estações climáticas: seca (abril a setembro) e chuvosa (outubro a março), entretanto não houve pesagem nos meses de janeiro e fevereiro. As fazendas foram agrupadas de acordo com a região ou semelhança de manejo e as observações em classes de idade (em anos), no dia da pesagem.

Foram realizadas análises de variância pelo método dos quadrados mínimos, por intermédio do Proc GLM do pacote SAS (1995). Após análises preliminares, foi adotado, para as vacas, um modelo linear incluindo os efeitos fixos de estado reprodutivo, estádio da lactação, estação, fazenda, idade e grupo genético, as interações de estação por estado reprodutivo, estádio da lactação e idade e o efeito aleatório de vaca dentro de grupo genético e fazenda. As duas primeiras interações foram retiradas do modelo nas análises da altura e do peso/altura, por não terem apresentado significância estatística nas análises preliminares $(\mathrm{P}>0,05)$. Este modelo, em que o grupo genético entra como variável de classificação, será referido como modelo [1].

O modelo para as novilhas incluiu os efeitos fixos de estação, fazenda, idade e grupo genético, a interação época $x$ idade e o efeito aleatório de novilha dentro de grupo genético e fazenda.

A variação entre pais não foi incluída no modelo, por estar confundida com os efeitos de fazenda (Madureira, 2001). Nas análises preliminares, foram testados modelos incluindo os efeitos de ano de nascimento ou ano de pesagem, que, entretanto, não permaneceram no modelo, porque não alteraram os valores de soma de quadrados, tirando, no entanto, muitos graus de liberdade do erro.

Testes aproximados de $\mathrm{F}$ para fazenda e grupo genético, da forma $\mathrm{F}=$ quadrado médio do efeito $/\left(\widehat{\sigma}_{\mathrm{e}}^{2}\right.$ $+\mathrm{k} \widehat{\sigma}{ }_{\mathrm{a}}^{2}$ ), foram construídos segundo Freund \& Littell (1981), sendo $\hat{\sigma} \mathrm{e}^{2}$ e $\widehat{\sigma}{ }_{\mathrm{a}}^{2}$ as estimativas das variâncias do erro e de animal e $\mathrm{k}$ a constante no valor esperado do quadrado médio de animal. As comparações de médias foram feitas pelo teste de Scheffé (1967). A repetibilidade foi calculada por meio da expressão $\mathrm{r}=\widehat{\sigma}_{\mathrm{a}}^{2} /\left(\hat{\sigma}_{\mathrm{a}}^{2}+\hat{\sigma}_{\mathrm{e}}^{2}\right)$.

Às médias obtidas pelos quadrados mínimos com o modelo [1] $\left(\bar{Y}_{\mathrm{i}}, \mathrm{i}=1, \ldots, 6\right)$, ponderadas pela inversa de sua variância $\left(\mathrm{w}_{\mathrm{i}}=1 / \widehat{\sigma}_{\mathrm{Yi}}{ }^{2}\right)$, foi ajustado um modelo aditivo dominante.

$$
\bar{Y}_{\mathrm{i}} \mathrm{w}_{\mathrm{i}}=\mathrm{b}_{0}+\mathrm{g}^{\mathrm{I}} \mathrm{q}_{\mathrm{i}}+\mathrm{h}^{\mathrm{I}} \mathrm{z}_{\mathrm{i}}+\mathrm{e}_{\mathrm{i}}, \quad \ldots \ldots
$$

em que $b_{0}$ é o intercepto, correspondente ao Guz puro; $\mathrm{q}_{\mathrm{i}}$, a proporção esperada de genes HVB nos indivíduos do i-ésimo grupo genético; $\mathrm{g}^{\mathrm{I}}$, a diferença aditiva individual entre ambas raças; $z_{i}$, a heterozigose racial ou proporção esperada de locos ocupados com um gene de cada raça; $\mathrm{h}^{\mathrm{I}}$, a heterose individual; e $\mathrm{e}_{\mathrm{i}}$, resíduo associado a cada média.

No modelo [2], a fração de HVB $\geq 31 / 32$ foi considerada igual a 1 , sendo os valores de heterozigose racial iguais a $1 / 2,1,30 / 64,1 / 2,1 / 4 \mathrm{e} 0$, para os grupos genéticos $1 / 4,1 / 2,5 / 8,3 / 4,7 / 8$ e $\geq 31 / 32$, respectivamente.

No modelo genético [2], descrito por Dickerson (1969), o parâmetro $h^{\mathrm{I}}$ mede o efeito da heterose individual, devido à dominância e à epistasia. Nos casos em queh ${ }^{\mathrm{I}}$ não foi significativa, ela foi retirada do modelo. Discussão dos modelos para predizer o desempenho dos cruzamentos foi apresentada por Madalena (2001).

O ajuste do modelo aditivo-dominante [2] foi avaliado por meio de um teste de $\mathrm{F}$, tendo no numerador o quadrado médio do erro do modelo [2] (a variação entre as médias dos grupos não explicada pelas regressões) e no denominador, a mesma expressão $\widehat{\sigma}_{\mathrm{e}}{ }^{2}+\mathrm{k} \widehat{\sigma}_{\mathrm{a}}{ }^{2}$ utilizada para testar os grupos genéticos no modelo [1].

\section{Resultados e Discussão}

Todas as fontes de variação sob o modelo [1] foram significativas para as três características de vacas $(\mathrm{P}<0,05)$, à exceção do efeito de estação do ano sobre a altura na cernelha $(\mathrm{P}=0,65)$, do efeito do estádio da lactação sobre a razão peso/altura $(\mathrm{P}=0,10)$ e dos efeitos de fazenda e grupo genético sobre peso/altura $(\mathrm{P}=0,05)$. As novilhas sofreram influência de fazenda, grupo genético e classes de idade, para as três características estudadas $(\mathrm{P}<0,05)$. A estação influenciou o peso corporal e a razão peso e altura, mas não influenciou a altura na cernelha $(P=0,84)$. A interação de idade $x$ estação somente foi significativa para peso corporal $(\mathrm{P}<0,05)$.

$\mathrm{Na}$ Tabela 1, são apresentados os coeficientes de variação, coeficientes de determinação e repetibilidades para as características estudadas. A repetibilidade da altura na cernelha foi maior que os valores obtidos para as outras duas características, confirmando que as medidas lineares são pouco (Mackay et al., 1989; Winkler, 1993; Winkler etal., 1992) ou nada (Bhaudaria \& Joha, 1986) influenciadas por mudanças temporárias de meio. 
Tabela 1 - Graus de liberdade (G.L.), coeficientes de variação residual (CV), coeficientes de determinação ( $\left.R^{2}\right)$, repetibilidades e desvios-padrão residuais $\left(\sigma_{e}^{2}\right)$

Table 1 - Degrees of freedom (d.f.), coefficients of residual variation (CV), coefficients of determination $\left(R^{2}\right)$, repeatibilities and residual standard deviations $\left(\sigma_{e}{ }^{2}\right)$

\begin{tabular}{|c|c|c|c|c|c|c|}
\hline & \multicolumn{3}{|c|}{$\begin{array}{l}\text { Vacas } \\
\text { Cows }\end{array}$} & \multicolumn{3}{|c|}{$\begin{array}{l}\text { Novilhas } \\
\text { Heifers }\end{array}$} \\
\hline & $\begin{array}{l}\text { Peso }(\mathrm{kg}) \\
\text { Weight }\end{array}$ & $\begin{array}{c}\text { Altura }(\mathrm{cm}) \\
\text { Height }\end{array}$ & $\begin{array}{c}\text { Peso/Altura }(\mathrm{kg} / \mathrm{cm}) \\
\text { Weight } / \text { Height }\end{array}$ & $\begin{array}{c}\text { Peso }(\mathrm{kg}) \\
\text { Weight }\end{array}$ & $\begin{array}{c}\text { Altura }(\mathrm{cm}) \\
\text { Height }\end{array}$ & $\begin{array}{c}\text { Peso/Altura }(\mathrm{kg} / \mathrm{cm}) \\
\text { Weight/Height }\end{array}$ \\
\hline $\begin{array}{l}\text { G.L.animal } \\
\text { d.f. animal }\end{array}$ & 230 & 203 & 203 & 157 & 125 & 125 \\
\hline $\begin{array}{l}\text { G.L. resíduo } \\
\text { d.f. residual }\end{array}$ & 1187 & 1063 & 1063 & 159 & 118 & 118 \\
\hline $\mathrm{R}^{2}$ & 0,80 & 0,91 & 0,75 & 0,86 & 0,92 & 0,80 \\
\hline $\mathrm{CV}, \%$ & 8,16 & 1,40 & 8,16 & 9,89 & 1,92 & 10,15 \\
\hline$\sigma_{\mathrm{e}}^{2}$ & 35,50 & 1,827 & 0,275 & 37,10 & 2,44 & 0,30 \\
\hline $\begin{array}{l}\text { Repetibilidade } \\
\text { Repeatability }\end{array}$ & 0,53 & 0,83 & 0,42 & 0,60 & 0,74 & 0,47 \\
\hline
\end{tabular}

Como pode ser observado na Tabela 2, as vacas vazias apresentaram menor peso corporal e menor razão entre peso/altura, características que aumentaram com o progresso da gestação, como esperado em decorrência do ganho em peso do feto, anexos fetais e peso corporal do próprio animal. A influência deste efeito sobre a razão peso/altura seria esperada, já que esta é considerada uma medida que reflete a condição corporal das fêmeas, como sugerem diversos autores (Klosterman et al., 1968; Thompson et al., 1983; Nelsen et al., 1985; Nicholson \& Sayers, 1987). Os efeitos do estado reprodutivo sobre a altura foram de pouca importância, concordando com as observações de Mckay et al. (1989), Winkler (1993) e Winkler et al. (1992).

Pode ser observada na Tabela 2 pequena tendência de diminuição do peso corporal com o aumento dos dias em lactação, ao contrário do encontrado por vários autores (Namjoshi \& Katpatal, 1983; Ruvuna et al., 1986; Nicholson \& Sayers, 1987), que observaram maior peso corporal nos estádios finais da lactação e para animais no período seco. Entretanto, neste experimento, apesar de algumas diferenças terem sido significativas $(\mathrm{P}<0,05)$, os efeitos do estádio da lactação sobre as três características estudadas foram de pequena magnitude, principalmente na característica altura na cernelha (Tabela 2).

A média de peso das vacas na estação seca foi $12 \mathrm{~kg}$ superior à da estação chuvosa (Tabela 2). Também foi maior a razão peso/altura, o que indica melhor condição corporal na época da seca. Entre- tanto, a diferença de peso entre as estações poderia estar sendo subestimada, pelo fato de não ter havido pesagens nos meses de janeiro e fevereiro, presumivelmente meses dos mais favoráveis da estação chuvosa.

O efeito de fazenda influenciou significativamente $(\mathrm{P}<0,01)$ as três características estudadas nas vacas e está, provavelmente, caracterizando os vários tipos de manejo utilizados nas fazendas cooperadoras deste experimento. $\mathrm{O}$ efeito de fazenda teve amplitudes de $-76 \mathrm{a}+75 \mathrm{~kg}$ para peso corporal, $-2,73 \mathrm{a}+6,32 \mathrm{~cm}$ para altura na cernelha e $-0,475 \mathrm{a}+0,355 \mathrm{~kg} / \mathrm{cm}$ para razão peso/altura.

Pode ser notado na Tabela 3 que as vacas continuaram ganhando peso, altura e condição corporal até aos nove anos de idade, embora as diferenças não tenham sido grandes a partir dos seis anos $(\mathrm{P}>0,42)$. Isto, provavelmente, se deve ao fato, citado por Mckay (1989), de que há diminuição na taxa de crescimento quando se chega à maturidade, obtida entre 6 e 8 anos. Joandet \& Cartwright (1969) observaram que o peso à maturidade foi atingido entre as idades de 5 e 9 anos.

Embora os pesos de vacas tomados na estação chuvosa continuaram a aumentar em todas as idades, eles diminuíram a partir dos sete anos quando tomados na seca, o mesmo acontecendo com a razão peso/ altura. Para altura na cernelha as tendências foram semelhantes em ambas estações. Entretanto, no final do experimento, à medida que vacas iam saindo do rebanho, em decorrência da própria idade, o número de observações era menor e sua distribuição nas 
Tabela 2 - Médias estimadas pelo método dos quadrados mínimos + erros-padrão (ep) para os efeitos de estado reprodutivo, estádio da lactação, e estação nas características de vacas

Table 2 - Least-square means + standard errors (se) for the effects of reproductive status, days in milk and season on cow traits

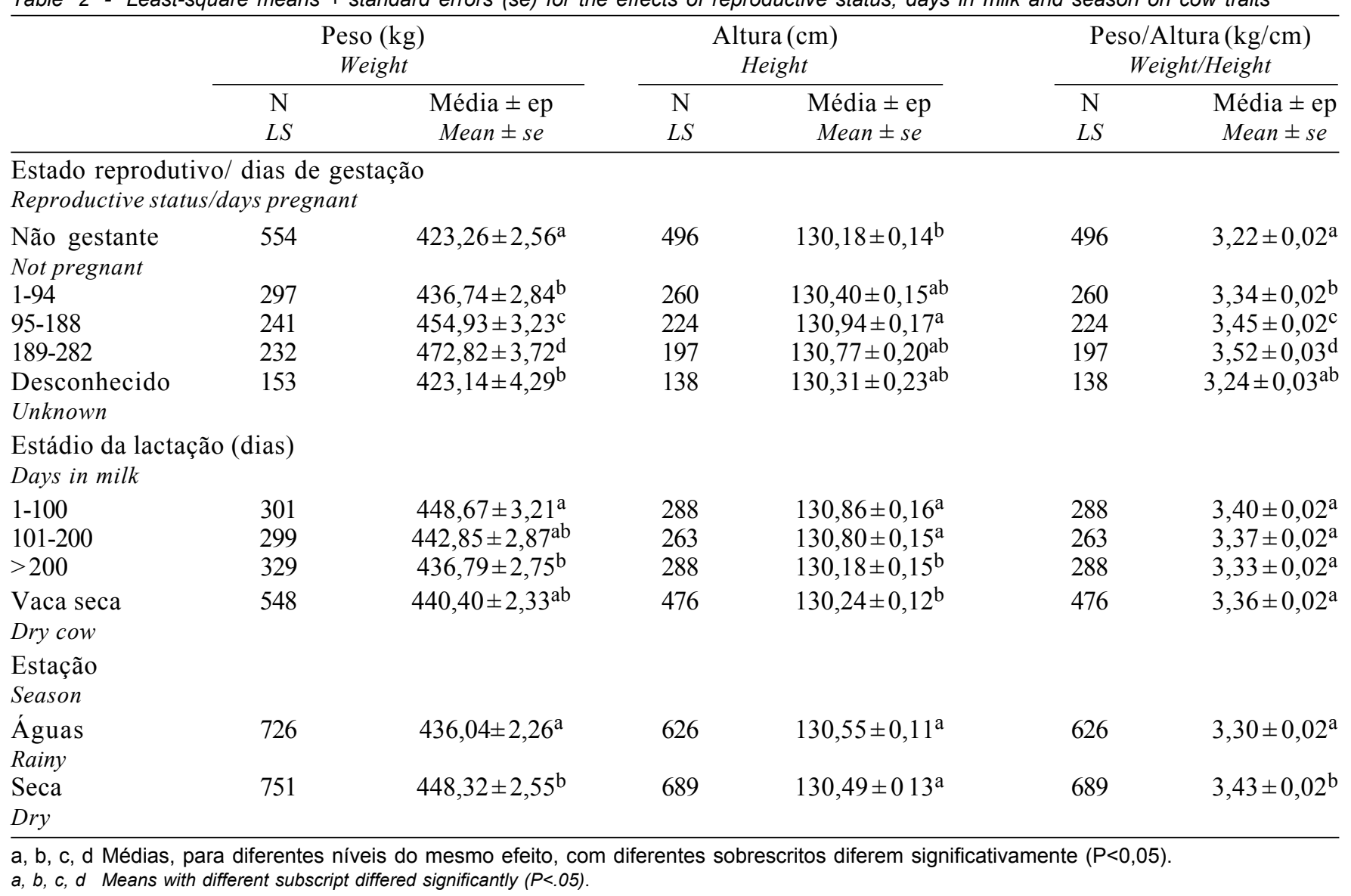

fazendas, grupos genéticos e outros fatores poderia ter afetado os resultados.

A diferença para os pesos nas estações seca e chuvosa para as vacas vazias e no primeiro terço da gestação foi de 13,9 e $12,7 \mathrm{~kg}$, respectivamente, ampliando-se para $25,9 \mathrm{~kg}$ no segundo terço de gestação e caindo para $1,6 \mathrm{~kg}$ no último terço, o que gerou a interação de estação x estado reprodutivo. Não se oferece nenhuma explicação para isto, embora seja concebível que melhor manejo no período pré-parto possa diminuir as diferenças de pesos entre as estações ao final da gestação. A interação entre estádio da lactação e estação do ano decorreu da diferença entre os pesos das vacas secas nas estações seca e chuvosa $(22,29 \mathrm{~kg})$, que foi maior que a diferença entre os pesos das vacas em lactação naquelas estações (4,14 a 15,14kg). Também não aparece uma explicação clara para este fato.

As vacas F1 apresentaram as maiores médias de peso corporal, assim como da razão peso/altura (Tabela 3). Resultados no mesmo sentido, para peso corporal, foram encontrados por Katpatal (1977), Bhat et al. (1978), Sharma et al. (1981) e Narayanaswamy et al. (1984), trabalhando com cruzamentos de Holandês x Sahiwal, e por Roy \& Tripathi (1991), com cruzamentos de Holandês x Sahiwal e Tharparkar.

Perotto et al. (1997) observaram para os cruzamentos Holandês-Zebu (Guzerá e Gir) valores de peso corporal à maturidade um pouco acima dos encontrados nesta pesquisa, de $484 \mathrm{~kg}$ para a F1 e $480 \mathrm{~kg}$ para $3 / 4$ HVB-Guz, mas que corroboram os presentes resultados, na medida em que apresentam as vacas $F 1$ como as mais pesadas seguidas das $3 / 4$.

As médias pelos quadrados mínimos para as características de novilhas apresentam-se na Tabela 4. A média de peso das novilhas na estação seca foi superior em $48 \mathrm{~kg}$ ao da estação chuvosa, apresentando também melhor indicativo de condição corporal (peso/altura) naquela estação.

Observa-se, na Tabela 4, que as novilhas F1 apresentaram-se mais pesadas, concordando com os 
Tabela 3 - Médias estimadas pelo método dos quadrados mínimos + erros-padrão (ep) para os efeitos de grupo genético e idade nas características de vacas

Table 3 - Least square means + standard errors (se) for genetic group and age effects on cow traits

\begin{tabular}{|c|c|c|c|c|c|c|}
\hline & \multicolumn{2}{|c|}{$\begin{array}{l}\text { Peso }(\mathrm{kg}) \\
\text { Weight }\end{array}$} & \multicolumn{2}{|c|}{$\begin{array}{c}\text { Altura }(\mathrm{cm}) \\
\text { Height }\end{array}$} & \multicolumn{2}{|c|}{$\begin{array}{c}\text { Peso/Altura }(\mathrm{kg} / \mathrm{cm}) \\
\text { Weight } / \text { Height }\end{array}$} \\
\hline & $\begin{array}{l}\mathrm{N} \\
L S\end{array}$ & $\begin{array}{l}\text { Média } \pm \text { ep } \\
\text { Mean } \pm \text { se }\end{array}$ & $\begin{array}{l}\mathrm{N} \\
L S\end{array}$ & $\begin{array}{l}\text { Média } \pm \text { ep } \\
\text { Mean } \pm \text { se }\end{array}$ & $\begin{array}{l}\mathrm{N} \\
L S\end{array}$ & $\begin{array}{c}\text { Média } \pm \text { ep } \\
\text { Mean } \pm s e\end{array}$ \\
\hline $1 / 4 \mathrm{HVB}^{1}$ & 251 & $440,67 \pm 8,96^{\mathrm{ab}}$ & 222 & $134,33 \pm 0,94^{\mathrm{a}}$ & 222 & $3,25 \pm 0,06^{\mathrm{acd}}$ \\
\hline $1 / 2 \mathrm{HVB}$ & 334 & $464,72 \pm 8,25^{\mathrm{a}}$ & 296 & $131,61 \pm 0,85^{\mathrm{ab}}$ & 296 & $3,49 \pm 0,05^{b}$ \\
\hline 5/8HVB & 215 & $449,98 \pm 9,77^{\mathrm{ab}}$ & 197 & $131,13 \pm 0,01^{\mathrm{ab}}$ & 197 & $3,42 \pm 0,06^{b c}$ \\
\hline $3 / 4 \mathrm{HVB}$ & 258 & $452,03 \pm 8,77^{\mathrm{ab}}$ & 233 & $131,21 \pm 0,94^{\mathrm{ab}}$ & 233 & $3,43 \pm 0,06^{b c}$ \\
\hline 7/8 HVB & 240 & $433,22 \pm 10,27^{\mathrm{ab}}$ & 213 & $129,79 \pm 0,04^{b c}$ & 213 & $3,33 \pm 0,07^{\mathrm{acd}}$ \\
\hline$\geq 31 / 32 \mathrm{HVB}$ & 178 & $412,47 \pm 10,55^{\mathrm{b}}$ & 154 & $125,07 \pm 0,07^{\mathrm{c}}$ & 154 & $3,26 \pm 0,07^{\mathrm{d}}$ \\
\hline \multirow{2}{*}{\multicolumn{7}{|c|}{$\begin{array}{l}\text { Idade (anos) } \\
\text { Age (years) }\end{array}$}} \\
\hline & & & & & & \\
\hline 3 & 183 & $392,97 \pm 3,27^{\mathrm{a}}$ & 158 & $127,85 \pm 0,17^{\mathrm{a}}$ & 158 & $3,06 \pm 0,03^{\mathrm{a}}$ \\
\hline 4 & 362 & $413,59 \pm 2,29^{b}$ & 313 & $129,73 \pm 0,12^{b}$ & 313 & $3,15 \pm 002^{\mathrm{a}}$ \\
\hline 5 & 365 & $435,20 \pm 2,44^{\mathrm{c}}$ & 303 & $130,30 \pm 0,13^{\mathrm{c}}$ & 303 & $3,32 \pm 0,02^{b}$ \\
\hline 6 & 288 & $451,03 \pm 2,61^{\mathrm{d}}$ & 265 & $131,02 \pm 0,14^{\mathrm{d}}$ & 265 & $3,43 \pm 0,02^{\mathrm{c}}$ \\
\hline 7 & 179 & $460,91 \pm 3,28^{d}$ & 163 & $131,37 \pm 0,17^{\mathrm{d}}$ & 163 & $3,50 \pm 0,03^{c}$ \\
\hline 8 & 73 & $467,78 \pm 5,00^{d}$ & 73 & $131,58 \pm 0,26^{\mathrm{d}}$ & 73 & $3,53 \pm 0,04^{\mathrm{c}}$ \\
\hline 9 & 40 & $473,78 \pm 6,25^{\mathrm{d}}$ & 40 & $131,81 \pm 0,32^{\mathrm{d}}$ & 40 & $3,55 \pm 0,05^{\mathrm{c}}$ \\
\hline
\end{tabular}

${ }^{1} \mathrm{HVB}=$ Red and white Holstein-Friesian.

a, b, c, d Médias, para diferentes níveis do mesmo efeito, com diferentes sobrescritos diferem significativamente $(P<0,05)$.

$a, b, c, d$ Means with different subscript differed significantly $(P<.05)$.

resultados observados por vários autores (Panda \& Sadhu, 1973; Katpatal, 1977; Namjoshi \& Katpatal, 1983; Pandey et al., 1985; Roy \& Tripathi, 1991; Perotto et al., 1997), e com melhor indicativo de condição corporal que os demais grupos genéticos. Observa-se, também, que as novilhas apresentaram maiores peso e altura e melhoraram a condição corporal com o avançar da idade.

As amplitudes dos efeitos de classe de fazenda nas características das novilhas foram, respectivamente para peso, altura e para a razão peso/altura de $-104,18$ a $+47,82 \mathrm{~kg},-3,21$ a $+2,83 \mathrm{~cm}$ e $-0,545$ a $+0,025 \mathrm{~kg} / \mathrm{cm}$.

As diferenças entre os pesos das novilhas nas estações seca e chuvosa foram de 97, 39, 36 e $16 \mathrm{~kg}$, respectivamente, para as idades dois a cinco anos, gerando a interação de estação x idade, mas não é claro que este fato tenha uma interpretação biológica, podendo talvez estar associado à distribuição das observações, que na classe de dois e, principalmente, na de cinco anos não era numeroso (13 e 7 em cada estação).

Os valores de $\mathrm{F}$ para avaliar o ajuste do modelo aditivo-dominante não foram significativos $(\mathrm{P}>0,05)$ nem nas vacas nem nas novilhas, para nenhuma das características medidas, indicando que outros fatores, como a epistasia, não foram importantes, além da diferença aditiva entre as raças e a heterose. Deve ser salientado, porém, que nos cruzamentos utilizados existia confundimento entre a heterozigose individual e a fração de HVB materna, isto é $\mathrm{z}_{\mathrm{i}}^{\mathrm{I}}=1-\mathrm{q}^{\mathrm{M}}{ }_{\mathrm{i}}$ para todos os grupos menos o $5 / 8$, de forma que os efeitos atribuídos à heterose individual $\left(\mathrm{h}^{\mathrm{I}}\right)$ poderiam estritamente ter sido causados por uma diferença aditiva materna entre as raças $\left(-\mathrm{g}^{\mathrm{M}}\right)$, embora isto não parece provável, já que os animais foram criados artificialmente. De todo modo, este fato não tira a validade do modelo para fins de predição do desempenho de cruzamentos não incluídos no experimento, a principal motivação para se pesquisar um modelo genético neste trabalho.

A diferença aditiva entre as raças (HVB menos Guz) não foi significativa para o peso corporal das vacas nem das novilhas (Tabela 5), diferentemente do efeito da heterose, que teve importante contribuição, especialmente nas novilhas, em que a heterose foi mais do dobro que nas vacas. Resultados no mesmo sentido foram encontrados por Teodoro et al. (1984) para peso à puberdade em outra amostra de novilhas do mesmo projeto.

Os valores esperados dos pesos corporais para os diferentes grupos genéticos, sob os modelos [1], classificatório e [2], aditivo-dominante, podem ser 
Tabela 4 - Médias estimadas pelo método dos quadrados mínimos + erros-padrão (ep) para os efeitos principais nas características de novilhas

Table 4 - Least square means + standard errors (se) for main effects in heifer traits

\begin{tabular}{|c|c|c|c|c|c|c|}
\hline & \multicolumn{2}{|c|}{$\begin{array}{l}\text { Peso }(\mathrm{kg}) \\
\text { Weight }\end{array}$} & \multicolumn{2}{|c|}{$\begin{array}{c}\text { Altura }(\mathrm{cm}) \\
\text { Height }\end{array}$} & \multicolumn{2}{|c|}{$\begin{array}{c}\text { Peso/Altura }(\mathrm{kg} / \mathrm{cm}) \\
\text { Weight/Height }\end{array}$} \\
\hline & $\begin{array}{l}\mathrm{N} \\
L S\end{array}$ & $\begin{array}{l}\text { Média } \pm \text { ep } \\
\text { Mean } \pm \text { se }\end{array}$ & $\begin{array}{l}\mathrm{N} \\
L S\end{array}$ & $\begin{array}{l}\text { Média } \pm \mathrm{ep} \\
\text { Mean } \pm \text { se }\end{array}$ & $\begin{array}{l}\mathrm{N} \\
L S\end{array}$ & $\begin{array}{l}\text { Média } \pm \mathrm{ep} \\
\text { Mean } \pm \text { se }\end{array}$ \\
\hline $\begin{array}{l}\text { Estação } \\
\text { Season }\end{array}$ & & & & & & \\
\hline $\begin{array}{l}\text { Águas } \\
\text { Rainy }\end{array}$ & 148 & $385,49 \pm 5,07^{\mathrm{a}}$ & 119 & $128,96 \pm 0,38^{a}$ & 119 & $3,04 \pm 0,05^{\mathrm{a}}$ \\
\hline $\begin{array}{l}\text { Seca } \\
\text { Dry }\end{array}$ & 189 & $432,94 \pm 5,51^{\mathrm{b}}$ & 137 & $128,87 \pm 0,42^{\mathrm{a}}$ & 137 & $3,34 \pm 0,05^{\mathrm{b}}$ \\
\hline $\begin{array}{l}\text { Grupo genéti } \\
\text { Genetic group }\end{array}$ & & & & & & \\
\hline $\begin{array}{l}1 / 4 \mathrm{HVB}^{1} \\
1 / 2 \mathrm{HVB} \\
5 / 8 \mathrm{HVB} \\
3 / 4 \mathrm{HVB} \\
7 / 8 \mathrm{HVB} \\
\geq 31 / 32 \mathrm{HVB}\end{array}$ & $\begin{array}{l}66 \\
33 \\
81 \\
45 \\
55 \\
57\end{array}$ & $\begin{array}{l}408,46 \pm 12,37^{\mathrm{abc}} \\
465,61 \pm 16,60^{\mathrm{b}} \\
393,25 \pm 12,21^{\mathrm{ac}} \\
418,18 \pm 14,24^{\mathrm{ab}} \\
411,46 \pm 13,87^{\mathrm{abc}} \\
358,33 \pm 14,23^{\mathrm{c}}\end{array}$ & $\begin{array}{l}52 \\
24 \\
61 \\
32 \\
40 \\
47\end{array}$ & $\begin{array}{l}133,28 \pm 1,21^{\mathrm{a}} \\
131,44 \pm 1,71^{\mathrm{ab}} \\
127,14 \pm 1,13^{\mathrm{bc}} \\
129,62 \pm 1,47^{\mathrm{abc}} \\
127,73 \pm 1,31^{\mathrm{bc}} \\
124,29 \pm 1,46^{\mathrm{c}}\end{array}$ & $\begin{array}{l}52 \\
24 \\
61 \\
32 \\
40 \\
47\end{array}$ & $\begin{array}{l}3,07 \pm 0,06^{\mathrm{a}} \\
3,55 \pm 0,08^{\mathrm{b}} \\
3,09 \pm 0,05^{\mathrm{a}} \\
3,15 \pm 0,07^{\mathrm{a}} \\
3,25 \pm 0,06^{\mathrm{ab}} \\
3,02 \pm 0,07^{\mathrm{a}}\end{array}$ \\
\hline $\begin{array}{l}\text { Idade (anos) } \\
\text { Age (year) }\end{array}$ & & & & & & \\
\hline $\begin{array}{l}2 \\
3 \\
4 \\
5 \\
5\end{array}$ & $\begin{array}{c}79 \\
166 \\
72 \\
20\end{array}$ & $\begin{array}{l}318,48 \pm 7,96^{\mathrm{a}} \\
394,43 \pm 4,54^{\mathrm{b}} \\
442,05 \pm 6,72^{\mathrm{c}} \\
481,89 \pm 11,75^{\mathrm{d}}\end{array}$ & $\begin{array}{c}- \\
179 \\
60 \\
17\end{array}$ & $\begin{array}{l}- \\
126,11 \pm 0,22^{\mathrm{a}} \\
128,44 \pm 0,45^{\mathrm{b}} \\
132,20 \pm 0,79^{\mathrm{c}}\end{array}$ & $\begin{array}{c}- \\
179 \\
60 \\
17\end{array}$ & $\begin{array}{l}2,89 \pm 0,02^{\mathrm{a}} \\
3,20 \pm 0,05^{\mathrm{b}} \\
3,47 \pm 0,09^{\mathrm{c}}\end{array}$ \\
\hline
\end{tabular}

${ }^{1} \mathrm{HVB}=$ Red and white Holstein-Friesian.

a, b, c, d Médias, para diferentes níveis do mesmo efeito, com diferentes sobrescritos diferem significativamente $(P<0,05)$.

$a, b, c, d$ Means with different subscript differed significanly $(P<.05)$.

melhor visualizadas na Figura 1, na qual se observa o efeito da heterose refletido no maior peso dos animais F1. O peso corporal diminuiu quando a fração de genes HVB se afastou de $1 / 2$, diminuindo a heterozigose racial.

$\mathrm{O}$ valor da diferença aditiva entre as raças para a característica de altura na cernelha foi negativo e muito semelhante para vacas e novilhas (Tabela 5), mostrando que, neste ambiente, os animais com maior fração de genes da raça Guzerá apresentaram altura superior à dos animais com maior fração de genes da raça Holandesa. Observou-se, ainda, que a altura dos animais não sofreu interferência de heterose (Tabela 5), senão que, como pode ser observado na Figura 2, a altura diminuiu linearmente com o aumento da fração de genes HVB.

A razão peso/altura apresentou valores positivos para a diferença aditiva entre as raças em vacas e novilhas, mas nas últimas não alcançou significância estatística (Tabela 5), enquanto a heterose foi significativa e positiva em ambas as categorias. A importância da heterose, relativa à diferença aditiva entre as raças $\left(\mathrm{h}^{\mathrm{I}} / \mathrm{g}^{\mathrm{I}}\right)$, foi muito menor para a razão peso/ altura que para o peso apenas. Estes resultados são apresentados na Figura 3.

O paralelismo entre os gráficos nas Figuras 1 e 3 sugere que os grupos genéticos mais pesados tiveram também a melhor condição corporal, indicada pela razão peso/altura. De fato, a correlação entre as médias sob o modelo [1] (ponderadas) para ambas características foi de 0,92. Levando-se em consideração que a mantença da gordura requer menos energia que a da proteína, parece provável que as exigências de mantença por $\mathrm{kg}$ de peso sejam influenciadas pela composição racial, de forma que não necessariamente as vacas geneticamente mais pesadas terão maiores exigências, como já foi demonstrado por Herd (1995) em vacas Bos taurus. Menores exigências de mantença de vacas $B$. indicus que B. taurus foram comunicadas por Solis et al. (1988). Parece plausível, portanto, supor que as diferenças entre raças serão expressas nos cruzamentos, em função da fração de Holandês e da heterose, como 
Tabela 5 - Estimativas de parâmetros de cruzamentos \pm erro-padrão. Intercepto $\left(b_{0}\right)$, diferença aditiva entre as raças ( $g^{\prime}$, HVB menos Guz) e heterose $\left(\mathrm{h}^{\mathrm{l}}\right)$

Table 5 - Estimates of crossbreeding parameters \pm standard error. Intercept $\left(b_{0}\right)$, breed additive difference $(g l$, Holstein-Friesian minus Guzera) and heterosis $\left(h^{\prime}\right)$

\begin{tabular}{|c|c|c|c|}
\hline $\begin{array}{l}\text { Parâmetro } \\
\text { Parameter }\end{array}$ & $\begin{array}{l}\text { Peso }(\mathrm{kg}) \\
\text { Weight }\end{array}$ & $\begin{array}{c}\text { Altura }(\mathrm{cm}) \\
\text { Height }\end{array}$ & $\begin{array}{c}\text { Peso/Altura }(\mathrm{kg} / \mathrm{cm}) \\
\text { Weight } / \text { Height }\end{array}$ \\
\hline \multicolumn{4}{|l|}{ Vacas } \\
\hline \multicolumn{4}{|l|}{ Cows } \\
\hline $\mathrm{b}_{0}$ & $415,24 \pm 16,28^{* * *}$ & $137,04 \pm 1,66^{* * *}$ & $3,02 \pm 009^{* * *}$ \\
\hline$g^{\mathrm{I}}$ & $5,61 \pm 17,05^{\mathrm{ns}}$ & $-9,75 \pm 2,42^{* * *}$ & $0,27 \pm 0,10^{* *}$ \\
\hline$h^{I}$ & $51,42 \pm 13,40^{* * *}$ & $\mathrm{~ns}$ & $0,36 \pm 0,08^{* * *}$ \\
\hline $\mathrm{h}^{\mathrm{I}} / \mathrm{g}^{\mathrm{I}}$ & 9,17 & - & 1,33 \\
\hline \multicolumn{4}{|l|}{ Novilhas } \\
\hline \multicolumn{4}{|l|}{ Heifers } \\
\hline $\mathrm{b}_{0}$ & $342,93 \pm 34,62^{* * *}$ & $135,63 \pm 1,89^{* * *}$ & $2,61 \pm 0,24^{* * *}$ \\
\hline $\mathrm{g}^{\mathrm{I}}$ & $23,95 \pm 35,14^{\mathrm{ns}}$ & $-10,38 \pm 2,72^{* * *}$ & $0,41 \pm 0,24^{f}$ \\
\hline $\mathrm{h}^{\mathrm{I}}$ & $109,77 \pm 32,97^{* * *}$ & $\mathrm{~ns}$ & $0,65 \pm 0,24^{* *}$ \\
\hline $\mathrm{h}^{\mathrm{I}} / \mathrm{g}^{\mathrm{I}}$ & 4,58 & - & 1,58 \\
\hline
\end{tabular}

n.s. $\mathrm{P}>0,10 ;{ }^{\mathrm{P}}=0,09 ;{ }^{* *} \mathrm{P}<0,01 ;{ }^{* * *} \mathrm{P}<0,001$.

$n s, P>$. 10; $f$ P=.09; ${ }^{* *} P<.01 ;{ }^{* \star *} P<.001$.

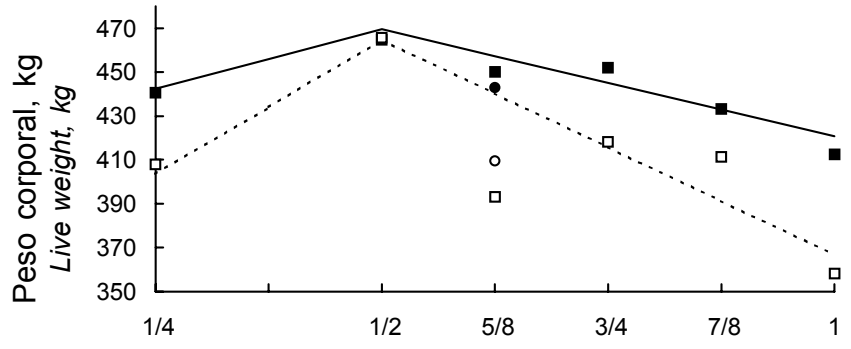

Fração de Holandês

Holstein-Friesian fraction

Figura 1 - Pesos corporais para os diferentes grupos genéticos HVB/Guzerá. Os valores esperados para as $F_{1} e$ retrocruzamentos sob o modelo aditivo dominante estão representados pelas linhas $(-=$ vacas, -- = novilhas) e os valores no mesmo modelo para as bimestiças $5 / 8$ pelos símbolos $0=$ vacas, $\bigcirc=$ novilhas. As médias pelos quadrados mínimos considerando o efeito de grupo genético classificatório, estão representadas pelos símbolos $\square=$ vacas, $\square=$ novilhas, para todos os cruzamentos.

Figure 1 - Liveweight of different Holstein-Friesian/Guzera cow genetic groups. The expected values for $F_{1}$ and backcrosses under the additive-dominance model are represented by lines ( $-=$ cows, $---=$ heifers) and values under the same model for inter se $5 / 8$ crosses by the symbols = cows, $\bigcirc=$ heifers. Least square means considering group effect as a class variable are represented by the symbols $\mathbf{\square}=$ cows, $\square=$ heifers for all crosses.

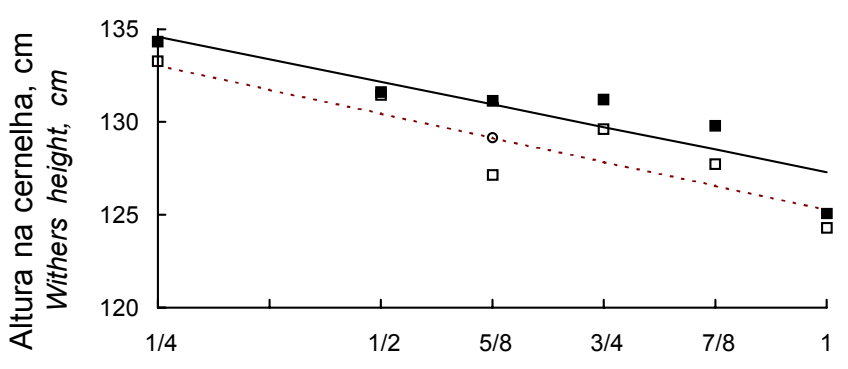

Fração de Holandês Holstein-Friesian fraction

Figura 2 - Altura na cernelha para os diferentes grupos genéticos HVB/Guzerá. Os valores esperados para as $F_{1}$ e retrocruzamentos sob o modelo aditivo dominante estão representados pelas linhas ( $-=$ vacas, $---=$ novilhas $)$ e os valores no mesmo modelo para as bimestiças $5 / 8$ pelos símbolos = vacas, $\bigcirc=$ novilhas. As médias pelos quadrados mínimos considerando o efeito de grupo genético classificatório, estão representadas pelos símbolos $\mathbf{\square}=$ vacas, $\square=$ novilhas, para todos os cruzamentos.

Figure 2 - Withers height of different Holstein-Friesian/Guzera cow genetic groups. The expected values for $F_{1}$ and backcrosses under the additive-dominance model are represented by lines $(-=$ cows, $---=$ heifers) and values under the same model for inter se $5 / 8$ crosses by the symbols 0 cows, $\mathrm{O}=$ heifers. Least square means considering group effect as a class variable are represented by the symbols $\mathbf{\square}=$ cows, $\square=$ heifers for all crosses. 


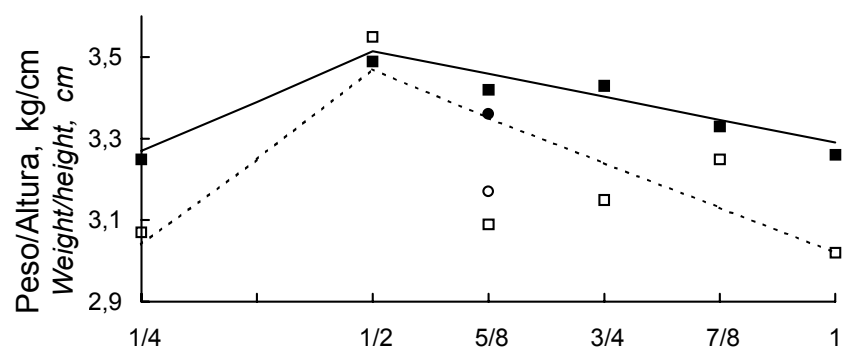

Fração de Holandês

Holstein-Friesian fraction

Figura 3 - Pesos/altura para os diferentes grupos genéticos HVB/Guzerá. Os valores esperados para as $\mathrm{F}_{1} \mathrm{e}$ retrocruzamentos sob o modelo aditivo dominante estão representados pelas linhas $(-=$ vacas, --- = novilhas) e os valores no mesmo modelo para as bimestiças $5 / 8$ pelos símbolos 0 = vacas, $\bigcirc=$ novilhas. As médias pelos quadrados mínimos considerando o efeito de grupo genético classificatório, estão representadas pelos símbolos $\square=$ vacas, $\square=$ novilhas, para todos os cruzamentos.

Figure 3 - Weight/height of different Holstein-Friesian/Guzera cow genetic groups. The expected values for $F_{1}$ and backcrosses under the additive-dominance model are represented by lines $(-=$ cows, $---=$ heifers) and values under the same model for inter se $5 / 8$ crosses by the symbols = cows, $\bigcirc=$ heifers. Least square means considering group effect as a class variable are represented by the symbols $\boldsymbol{\square}=$ cows, $\square=$ heifers for all crosses.

sucede para muitas outras características, o que deveria ser estudado especificamente, face à grande importância econômica do assunto.

Nas novilhas, os grupos genéticos mais pesados também tiveram a melhor condição corporal, indicada pela razão peso/altura, com uma correlação de 0,82 entre as médias para ambas características sob o modelo [1]. Isto pode ter influenciado a superioridade das $\mathrm{F} 1$ e a heterose favorável para idade à puberdade e ao primeiro parto encontradas em outros trabalhos deste projeto (Teodoro et al., 1984; Lemos et al., 1992).

Com uma amostra de animais do mesmo projeto, ganhando 500 ou $300 \mathrm{~g} /$ dia, verificou-se maior ganho de peso, consumo de alimento e eficiência de conversão para as novilhas F1 (Paiva et al., 1993), sendo a heterose favorável para a última característica (Madalena et al., 1992).

\section{Conclusões}

Peso corporal, altura na cernelha e razão peso/ altura foram fortemente influenciados pelo tipo de cruzamento, tanto nas vacas como nas novilhas. A altura não apresentou heterose, diminuindo linearmente com aumento da fração de HVB, as outras duas características foram máximas para o cruzamento F1 e diminuíram linearmente com menor heterozigose racial.

O modelo aditivo-dominante com apenas efeitos individuais foi suficiente para explicar a variação entre os cruzamentos, não havendo evidência de epistasia nestes resultados.

Como nas vacas a correlação entre as médias dos grupos genéticos para peso e peso/altura foi muito alta, indicando que os animais mais pesados tinham também melhor condição corporal, as exigências de mantença por kg de peso poderão ser diferentes nos diferentes cruzamentos, em função da provável variação em conteúdo de gordura e proteína na composição corporal dos mesmos. Os presentes resultados sugerem a necessidade de pesquisas específicas sobre o assunto.

\section{Literatura Citada}

BHAT, P.N.; TANEJA, V.K.; GARG, R.C. Body weight changes in Holstein $\mathrm{x}$ Sahiwal cross-bred in relation to level of Holstein inheritance. Indian Journal of Animal Science, v.48, p.485-491, 1978.

BHAUDARIA, S.S.; JOAH, K.S. Effect of various genetic and non-genetic factors on body measurements in Jersey cows. Journal of Dairy Science, v.39, p.291-296, 1986.

CARTWRIGHT, T.C. Size as a component of beef production efficiency: cow-calf production. Journal of Animal Science, v.48, p.974-980, 1979.

CUE, R.I.; HARRIS, B.L.; RENDEL, J.M. Genetic parameters for traits other than production in purebred and crossbred New Zealand dairy cattle. Livestock Production Science, v.45, p.123-135, 1996.

DICKERSON, G.E. Experimental approaches in utilizing breed resources. Animal Breeding Abstracts, v.37, p.191-202, 1969.

DICKERSON, G.E. Inbreeding and heterosis in animals. ANIMAL BREEDING AND GENETICS SYMP. IN HONOR OF DR. LAY L. LUSH, 1973, Champaign. Proceedings... Champaign: American Society of Animal Science, 1973. p.54-77.

FREUND, R.J.; LITTELL, R.C. SAS for linear models: A guide to the ANOVA and GLM procedures. Cary: SAS Institute, 1981. 
HERD, R.M. Effect of divergent selection for yearling growth rate on the maintenance feed requirements of mature Angus cows. Livestock Production Science, v.41, p.39-49, 1995.

JOANDET, G.E.; CARTWRIGHT, T.C. Estimation of efficiency of beef production, Journal of Animal Science, v.29, p.862-868, 1969.

KATPATAL., B.G. Dairy cattle crossbreeding in India: 1. Growth and development of crossbreeding. World Animal Review, v.22, p.15-21, 1977.

KLOSTERMAN, E.W.; SANFORD, L.G.; PARKER, C.F. Effect of cow size and condition and ration protein content upon maintenance requirements of mature beef cows. Journal of Animal Science, v.27, p.242-246, 1968.

LEMOS, A.M.; TEODORO, R.L.; BARBOSA, R.T. et al. Comparative performance of six Holstein-Friesian x Guzerá grades in Brazil. 1. Gestation length and birth weight. Animal Production, v.38, p.157-164, 1984.

LEMOS, A.M.; MADALENA, F.E.; TEODORO, R.L.; BARBOSA, R.T. et al. Comparative performance of six HolsteinFriesian x Guzerá grades in Brazil. 5. Age at first calving. Revista Brasileira de Genética, v.15, p.73-84, 1992.

MCKAY, R.M.; RAHNEFELD, G.W.; WEISS, G.M. et al. Live body measurements in ten first crosses of beef cows raised in two environments. Canadian Journal of Animal Science, v.69, p.69-82, 1989.

MADALENA, F.E. Técnicas de determinación del peso vivo en los bovinos. (Bol. Téc. Est. Exp. "Dr. Mario A. Cassinoni”, 1) Paysandú: 1964. p.49-54.

MADALENA, F.E. La utilización sostenible de hembras F1 en la producción del ganado lechero tropical. Roma: FAO, 1993. (Estudio FAO Producción y Sanidad Animal, 111).

MADALENA, F.E. Consideraciones sobre modelos para la predicción del desempeño de cruzamientos en bovinos Revisión bibliográfica. Archivos Latinoamericanos de Producción Animal, 2001 (prelo).

MADALENA, F.E.; PAIVA, J.A.J.; TEODORO, R.L. Comparative performance of six Holstein-Friesian x Guzera crossed groups in Brazil. 6. Breed additive and heterosis effects on components of feed conversion efficiency in heifers. Revista Brasileira de Genética, v.15, p.595-601, 1992.

MADUREIRA, A.P. Efeito da composição genética sobre o peso corporal e altura de fêmeas Holandês-Guzerá. Belo Horizonte: Universidade Federal de Minas Gerais, 2001. 51 p. Dissertação (Mestrado em Zootecnia) - Universidade Federal de Minas Gerais, 2001.

MARSHALL, T.E.; MOHLER, M.A.; STEWART, T.S. Relationship of lifetime productivity with mature weight and maturation rate in Red Poll cows. Animal Production, v.39, p.383-387, 1984.

MASON, I.L.; ROBERTSON, A.; GJELSTAD, B. The genetic connection between body size, milk production and efficiency in dairy cattle. Dairy Research, v.24, p.135-143, 1957.

NAMJOSHI, M.; KATPATAL; B.G. Studies on variance and relationship among body surface area, body weight and linear body measurements of zebu-taurus crosses. Indian Journal of Animal Science, v.53, p.1167-1171, 1983.

NARAYANASWAMY, M.; BALAINE, D.N.; RAM, S. Studies on growth efficiency in Friesian x Sahiwal crosses. Indian Journal of Dairy Science, v.34, p.44-49, 1984

NELSEN, T.C.; SHORT, R.E.; REYNOLDS, W.L. et al. Palpated and visually assigned condition scores compared with weight, height and heart girth in Hereford and crossbred cows. Journal of Animal Science, v.60, p.363-368, 1985.
NICHOLSON, M.J.; SAYERS, A.R. Repeatability, reproducibility and sequential use of condition scoring of Bos indicus cattle. Tropical Animal Health Production, v.19, p.127-135, 1987.

PAIVA, J.A.J.; MADALENA, F.E.; TEODORO, R.L. et al. Feed conversion efficiency in six groups of Holstein-Friesian $\mathrm{x}$ Guzera crosses. Livestock Production Science, v.30, p.213-222, 1993.

PANDA, P.B.; SADHU, D.P. Rate of growth of cross-bred heifers. Journal of Dairy Science, v.26, p.270-274, 1973.

PANDEY, H.N.; SRIVASTAVA, B.B.; NIVSARKAR, A.E. et al. Weight and linear body measurements at calving. Indian Journal of Dairy Science, v.38, p.250-255, 1985.

PEROTTO, D.; CASTANHO, M.J.P.; ROCHA, J.L. et al. Descrição das curvas de crescimento de fêmeas bovinas Guzerá, Gir, Holandês x Guzerá e Holandês x Gir. Revista Brasileira Zootecnia, v.26, p.283-288, 1997.

ROY, P.K.; TRIPATHI, V.N. Studies on body weights up to two years of age in Friesian x Sahiwal/Tharparkar crossbreds. Indian Veterinary Journal, v.68, p.174-176, 1991.

RUVUNA, F.; MCDOWELL, R.E.; CARTWRIGHT, T.C. et al. Growth and reproduction characteristics of purebred and crossbred dairy cattle in first lactation. Journal of Dairy Science, v.69, p.782-793, 1986.

SAS INSTITUTE. Statistical Analysis System. User's Guide. Cary: 1995.

SCHEFFÉ, H. The analysis of variance. London: John Wiley \& Sons, 1967. 477p.

SHARMA, J.M.; DHINGRA, M.M.; GURUNG, B.S. Note on factors body weights in Holstein $x$ Sahiwal crosses. Indian Journal of Animal Science, v.51, p.969-971, 1981.

SOLÍS, J.C., BYERS, F.M., SCHELLING, G.T. et al. Maintenance requirements and energetic efficiency of cows of different breeds. Journal of Animal Science, v.66, p.764-773, 1988.

TEODORO, R.L.; LEMOS, A.M.; BARBOSA, R.T. Comparative performance of six Holstein-Friesian x Guzera grades in Brazil. 2. Traits related to the onset of the sexual function. Animal Production, v.38, p.165-170, 1984.

THOMPSON, W.R.; THEUNINCK, D.H.; MEISKE, J.C. et al. Linear measurements and visual appraisal as estimators of percentage empty body fat of beef cows. Journal of Animal Science, v.56, p.755-760, 1983.

VERCESI FILHO, A.E.; MADALENA, F.E.; FERREIRA, J.J. Pesos econômicos para seleção de gado de leite. Revista Brasileira de Zootecnia, v.29, p.145-152, 2000.

WINKLER, R. Tamanho corporal e suas relações com algumas características reprodutivas em fêmeas bovinas adultas da raça Guzerá. Belo Horizonte: Universidade Federal de Minas Gerais, 1993. 116p. Dissertação (Mestrado em Zootecnia) - Universidade Federal de Minas Gerais, 1993.

WINKLER, R.; PENNA, V.M.; AULER, F. et al. Medidas corporais de fêmeas adultas da raça Guzerá. I. Médias e repetibilidades, In: REUNIÃO ANUAL DA SOCIEDADE BRASILEIRA DE ZOOTECNIA, 29., 1992, Lavras. Anais... Lavras: Sociedade Brasileira de Zootecnia, 1992. p.98.
Recebido em: 20/02/01 Aceito em: 24/10/01 